\title{
REFERENCES
}

Rouse A. (1991). Do ambulance crews triage trauma patients? Archives of Energency Medicine 8, 185-191?

Boyd C. R., Tolson M. A. \& Copes W. S. (1987). Evaluating trauma care: the TRISS method. The Journa of Traumia 27, 370-8.

\section{Should wearing of cycle helmets become compulsory?}

Sir

As a mild to moderate cyclist, (65 miles per week, mostly with a helmet!) I would $\overrightarrow{\dot{\omega}}$ like to question M. W. Cooke's suggestion that cycle helmet wearing should be compulsory.

Firstly, consider accident cause. In a series of 394 cycle injuries presenting to an A\&E department $63 \%$ were caused by the cyclist's inability to control the bike -.no vehicle or other factors were involved. We need to educate cyclists to ride prop-i erly, particularly the children.

Secondly, in the above study only $26 \%$ were involved in a collision with a motorvehicle. In a separate study of head injuries to cyclists (Worrell, 1987) $38 \%$ were caused by collision with a motor vehicle, but $58 \%$ just fell off. Agreed, a collision $\widehat{\widehat{S}}$ will produce a more serious injury, but we must educate motorists to look out $\vec{\bullet}$ for cyclists, and also to enforce existing speed limits $\left(E=1 \times 2 \mathrm{MV}^{-2}\right)$. Why shou\&d cyclists be compelled to protect themselves from the illegal acts of others?

Thirdly, this law would be totally unenforceable, a fact recognized by a recentit meeting of the House of Commons Select Committee on Transport, and sưr-⿳亠二口犬 prisingly backed by the Department of Transport!

Fourthly, he may not be aware that the BS for helmets is designed in such a way $\underset{\Rightarrow}{\stackrel{0}{\sharp}}$ that the helmet must withstand an impact on an angled edge, which makes the $\frac{0}{3}$ helmet hot and heavy to wear. The 'comfort factor' is one of the most important points in helmet use; those which are poorly ventilated and heavy will not be worn. Even serious racers who agree helmets are needed do not always wear them, viz: on the mountain stages of the last Tour de France, where extremes of effort and heat are encountered.

Yes, a helmet will help protect your head, but we should proceed by education rather than legislation.

\section{J. WORRELL}

Basingstoke District Hospital

Basingstoke

\section{REFERENCES}

Worrell J. (1987). Head injuries to pedal cyclists, will head protection help? Injury 18, 5-6. 